Portland State University

PDXScholar

Environmental Science and Management

Faculty Publications and Presentations

5-9-2017

\title{
Forecasted Range Shifts of Arid-Land Fishes in Response to Climate Change
}

James E. Whitney

University of Missouri

Joanna B. Whittier

University of Missouri

Craig Patrick Paukert

U.S. Geological Survey

Julian D. Olden

University of Washington - Seattle Campus

Angela L. Strecker

Portland State University, angela.strecker@wwu.edu

Follow this and additional works at: https://pdxscholar.library.pdx.edu/esm_fac

Part of the Climate Commons, Environmental Sciences Commons, and the Fresh Water Studies Commons

Let us know how access to this document benefits you.

Citation Details

Whitney, J. E., Whittier, J. B., Paukert, C. P., Olden, J. D., \& Strecker, A. L. (2017). Forecasted range shifts of arid-land fishes in response to climate change. Reviews in Fish Biology and Fisheries, 1-17.

This Article is brought to you for free and open access. It has been accepted for inclusion in Environmental Science and Management Faculty Publications and Presentations by an authorized administrator of PDXScholar. Please contact us if we can make this document more accessible: pdxscholar@pdx.edu. 


\title{
Forecasted range shifts of arid-land fishes in response to climate change
}

\author{
James E. Whitney · Joanna B. Whittier • Craig P. Paukert • Julian D. Olden • \\ Angela L. Strecker
}

Received: 23 July 2016/ Accepted: 4 May 2017

(C) Springer International Publishing Switzerland 2017

\begin{abstract}
Climate change is poised to alter the distributional limits, center, and size of many species. Traits may influence different aspects of range shifts, with trophic generality facilitating shifts at the leading edge, and greater thermal tolerance limiting contractions at the trailing edge. The generality of relationships between traits and range shifts remains ambiguous however, especially for imperiled fishes residing in xeric riverscapes. Our objectives were to quantify contemporary fish distributions in the Lower Colorado River Basin, forecast climate change by 2085 using two general circulation models, and
\end{abstract}

Electronic supplementary material The online version of this article (doi:10.1007/s11160-017-9479-9) contains supplementary material, which is available to authorized users.

J. E. Whitney

Missouri Cooperative Fish and Wildlife Research Unit, Department of Fisheries and Wildlife Sciences, University of Missouri, 302 Anheuser-Busch Natural Resources Building, Columbia, MO 65211, USA

\section{J. B. Whittier}

Department of Fisheries and Wildlife Sciences, University of Missouri, 302 Anheuser-Busch Natural Resources Building, Columbia, MO 65211, USA

C. P. Paukert

U.S. Geological Survey, Missouri Cooperative Fish and Wildlife Research Unit, Department of Fisheries and Wildlife Sciences, University of Missouri, 302 AnheuserBusch Natural Resources Building, Columbia, MO 65211, USA quantify shifts in the limits, center, and size of fish elevational ranges according to fish traits. We examined relationships among traits and range shift metrics either singly using univariate linear modeling or combined with multivariate redundancy analysis. We found that trophic and dispersal traits were associated with shifts at the leading and trailing edges, respectively, although projected range shifts were largely unexplained by traits. As expected, piscivores and omnivores with broader diets shifted upslope most at the leading edge while more specialized invertivores exhibited minimal changes. Fishes that were more mobile shifted upslope most at the trailing edge, defying predictions. No traits explained changes in range center or size. Finally, current preference

\section{J. D. Olden \\ School of Aquatic and Fishery Sciences, University of Washington, Seattle, WA 98195, USA}

\author{
A. L. Strecker \\ Department of Environmental Science and Management, \\ Portland State University, 1719 SW 10th Ave, Portland, \\ OR 97201, USA \\ Present Address: \\ J. E. Whitney $(\bowtie)$ \\ Department of Biology, Pittsburg State University, 223 Heck- \\ ert-Wells Hall, Pittsburg, KS 66762, USA \\ e-mail: jewhitney@ pittstate.edu
}


explained multivariate range shifts, as fishes with faster current preferences exhibited smaller multivariate changes. Although range shifts were largely unexplained by traits, more specialized invertivorous fishes with lower dispersal propensity or greater current preference may require the greatest conservation efforts because of their limited capacity to shift ranges under climate change.

Keywords Climate change - Imperiled fish . Nonnative fish $\cdot$ Range shifts $\cdot$ Rivers $\cdot$ Trait-based approach

\section{Introduction}

A broad diversity of plants and animals have shifted their ranges in response to changing climates in the past, and many are expected to do so in the coming decades (Parmesan and Yohe 2003; Hickling et al. 2006). Under climate change the maximum range elevation or latitude (i.e. the leading edge) is typically where range expansions and colonizations are occurring (Thomas 2010; La Sorte and Jetz 2012), whereas range contractions and local extinctions generally occur near the minimum elevation or latitude (i.e. the trailing edge; Hampe and Petit 2005; Cahill et al. 2012). Shifts in leading and trailing edges can alter other aspects of species' ranges, such as the range center (Crimmins et al. 2011) and size (Warren et al. 2001). The combined influence of these changes can lead to range contractions for some species (Urban 2015) and range expansions for others (Rahel and Olden 2008). Forecasting which species are likely to experience range contractions or expansions under climate change is important for successful conservation and management, so that vulnerable species can be identified before climate-induced extinction is imminent (Williams et al. 2008; Huey et al. 2012), or to allow preventative measures to be taken against nonnative species that are likely to spread (Rahel and Olden 2008).

In recent years, traits have demonstrated utility for explaining observed and predicted changes in species ranges, thus helping to create a mechanistic understanding of climate-induced range shifts and vulnerability across multiple species (Sunday et al. 2015; Estrada et al. 2016). For instance, traits related to establishment potential (i.e. dispersal, feeding, and life-history) may be most important in range expansions at the leading edge, as increased mobility, trophic generality, feeding at lower trophic levels, and greater propagule supply facilitate colonization of new habitats (Perry et al. 2005; Buckley 2012; Comte et al. 2014; Sunday et al. 2015). By contrast, at the trailing edge thermal tolerance is believed to be of paramount importance, with species more tolerant of higher temperatures likely to exhibit fewer range contractions (Buckley et al. 2013; Comte et al. 2014). In flowing water habitats, traits related to flow preference may also be important in dictating climate-induced range shifts, as changes in precipitation and increases in evapotranspiration associated with warmer temperatures may produce lower flows and increased intermittency, benefiting species adapted to more lentic conditions (Poff et al. 2010; Jaeger et al. 2014; Ruhi et al. 2016). Additionally, some of the aforementioned traits may exhibit a phylogenetic signal, thus allowing taxonomic relatedness to predict a species climate response (Roy et al. 2009; Thuiller et al. 2011). Finally, origin (i.e. native or nonnative) and conservation status may predict climate-induced range shifts, as the same traits that caused the imperilment of a native species or the successful establishment of a nonnative may also determine distributional shifts (Xenopoulos et al. 2005; Rahel and Olden 2008). Although trait-based analyses provide a promising approach for mechanistically understanding range shifts in response to climate change, further study is needed to assess the generality of trait associations with range shifts (Bates et al. 2014; Estrada et al. 2016).

Recent reviews have documented a limited number of studies of climate-induced range shifts of freshwater fishes in arid regions, and a disproportionate lack of attention given to imperiled species (Comte et al. 2013; Lynch et al. 2016). Climate change research in the Lower Colorado River Basin (LCRB) of the southwestern United States and northern Mexico could help address both of these challenges, as the LCRB drains one of the most arid regions in the world (Carlson and Muth 1989), and contains a native fish fauna that is highly imperiled from habitat degradation, fragmentation, and nonnative fishes (Olden et al. 2006; Paukert et al. 2011). Furthermore, climate change has already resulted in lower flows in the basin, with concomitant increases in the extinction risk 
of native fishes (Ruhi et al. 2016). Climate change is forecasted to further increase aridity in the region, with projections in the Upper CRB indicating higher temperatures coupled with minor changes in precipitation will result in greater evapotranspiration and decreasing soil moisture (Seager et al. 2013). Similarly, Christensen and Lettenmaier (2007) forecasted that higher temperatures and lower precipitation would result in lower runoff for the entire Colorado River Basin. The heightened aridity in the LCRB resulting from climate change poses potentially severe consequences to an already-imperiled native fish fauna.

Our study aimed to first quantify environmental variables describing contemporary fish ranges in the LCRB, and to forecast changes in temperature and precipitation under climate change. Using this information, we then sought to examine climate-induced shifts in the leading edge, trailing edge, center, and size of native and nonnative fish ranges, and evaluate associations among range shifts and species traits (i.e. origin, phylogeny, conservation status, thermal tolerance, flow preference, dispersal ability, and establishment potential). We predicted that traits related to dispersal and establishment potential would be most associated with shifts at the leading edge of ranges, with fishes exhibiting greater mobility, higher propagule supply, and or trophic generality shifting their leading edge most. At the trailing edge we predicted that thermal tolerance would best predict range shifts, with fishes with lower temperature preferences shifting more than species with higher temperature preferences. Next, we predicted that traits associated with larger shifts at the leading (i.e. greater mobility, propagule supply, and trophic generality) or trailing edge (i.e. colder temperature preferences) would cause the distributional center to shift by the greatest magnitude. Lastly, we predicted the largest range contractions for species with cold temperature preferences, preference for higher flows, and native species already imperiled by human activities. Investigating range shifts under future climate scenarios facilitates the development of management priorities by helping identify vulnerable native fishes that require the greatest conservation efforts, as well as nonnative fishes with the greatest need for control because of their potential range expansion (Olden et al. 2010). Furthermore, using a trait-based approach to investigate different aspects of range shifts could provide a mechanistic explanation of species responses to climate change, which could then be extended to other uninvestigated species to generate management recommendations (Estrada et al. 2016).

\section{Methods}

The LCRB drains parts of Utah, Nevada, California, Arizona, and New Mexico in the southwestern United States, and Sonora in northern Mexico (Fig. 1). Climate, geomorphology, hydrology, and human land use are spatially variable throughout the LCRB, with rivers draining mountainous and desert landscapes in a xeric climate (Online Resource 1; Paukert et al. 2011; Strecker et al. 2011). We used a comprehensive database of fish occurrence records spanning 1980-2009 to generate estimates of contemporary species ranges (Whittier et al. 2011; Strecker et al. 2011). Fish occurrence data recorded during or after 1980 represent contemporary distributional patterns in the Colorado River Basin (Olden and Poff 2005) and are appropriate for our analyses. This database included fish occurrence information (incidence, identity, and collection information) derived from museum collections, state and federal agency databases, and peer-reviewed and gray literature sources for $\sim 2000$ stream segments (i.e. a confluence to confluence section of stream; 72,889 total segments in the LCRB). See Strecker et al. (2011) and Whittier et al. (2011) for further information concerning the development of fish occurrence databases.

We used fish occurrence information to develop environmental niche models (ENMs) for native and nonnative fishes in the LCRB (Guisan and Thuiller 2005; Elith et al. 2010). The ENMs used abiotic environmental variables and species co-occurrences to predict the probability of occurrence for each species in each stream segment, allowing us to describe contemporary ranges and predict future ranges under climate change for the entire LCRB. The use of predicted occurrence probabilities in describing ranges was preferable to observed occurrences, given most ( $\sim 97 \%$ ) segments remain unsampled within our database. The ENMs were created using multiresponse (Elith et al. 2006) multivariate adaptive regression splines (MARS) models (Friedman 1991) implemented with functions from the mda library (Hastie and Tibshirani 1996) in program R (R Core 


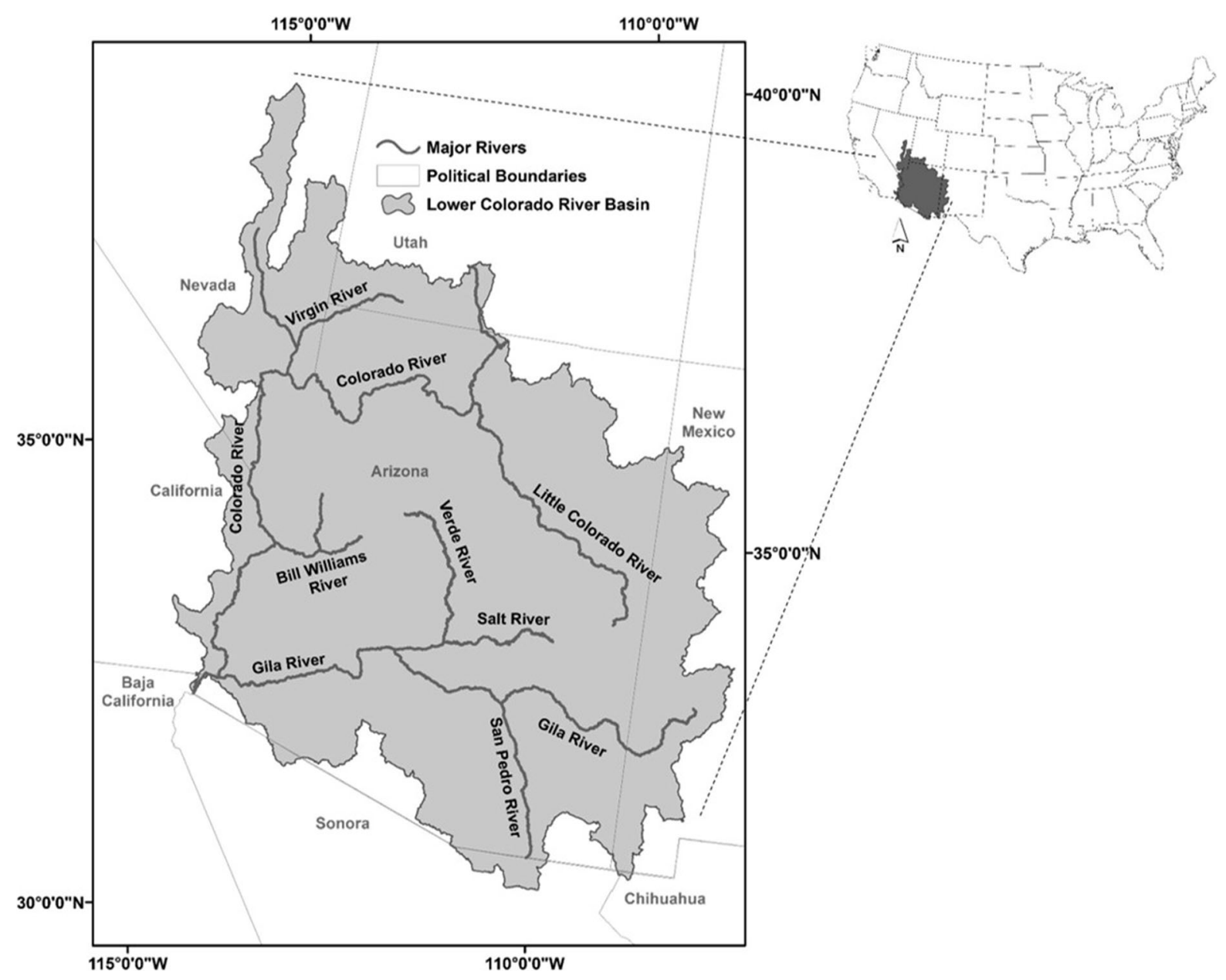

Fig. 1 Study area map indicating major tributaries of the Lower Colorado River Basin

Team 2015), which included modifications by Leathwick et al. (2005) to allow binomial error terms associated with presence/absence data. Our criteria for selecting species for environmental niche modeling from all of the fishes ever documented in the LCRB included that species had been collected as part of a community sampling effort (assuming $>2$ species in a sample $=$ community sample), were collected between 1980 and 2009, and had been found in a minimum of 30 unique stream segments. These criteria resulted in ENM creation for 18 native and 21 nonnative fishes (Online Resource 2). Environmental predictor variables used in ENMs were derived from a geographic information system (GIS) and represented variables describing the geomorphology, hydrology, climate, human land use, and biogeographical history of a stream segment. Predictor variables were selected based on results from Pool et al. (2010) and Strecker et al. (2011), which screened a broader set of GIS-derived environmental predictor variables to find those most important in describing fish distributions in the LCRB; see Whittier et al. (2011) for greater details concerning the development of GIS-derived predictor variables. Variables exhibiting high collinearity $(r>0.80)$ were not included in our set of environmental predictor variables. Model performance was assessed using the area under the Receiver Operating Characteristic curve (AUC [Fielding and Bell 1997]) calculated using a 10-fold crossvalidation, with AUC values $\geq 0.75$ indicating a model with good performance (Pearce and Ferrier 2000). The importance of environmental explanatory variables in predicting a species occurrence was defined according to the delta deviance of a variable if it had a 
statistically significant effect (i.e. $\alpha<0.05$ ) in an ENM. Delta deviance is the change in model fit when a predictor variable is removed from a model (MacCullagh and Nelder 1984); the more influential the predictor variable, the greater its delta deviance. Finally, the overall importance of an environmental predictor variable across all fishes was calculated according to the percentage of ENMs in which a predictor variable had a statistically significant effect.

\section{Climate change and range shifts}

We used two general circulation models (GCMs) to forecast future values of climate metrics included in our ENMs (i.e. mean annual temperature and precipitation; coefficient of variation [CV] of winter and spring precipitation). Specifically, dynamically downscaled precipitation and temperature metrics were generated using the ECHAM5 (otherwise known as MPEH5; Roeckner et al. 2003) and GENMOM GCMs (Alder et al. 2011). The ECHAM5 and GENMOM GCMs were chosen because they provide a range of climate predictions with regards to forecasts of the magnitude of climate change in Western North America (Hostetler et al. 2011). Further, ECHAM5 and GENMOM were selected because they are dynamically downscaled models, which, as opposed to statistically downscaled models (Stoner et al. 2013), provide greater ability to correct for topographic features (Hostetler et al. 2011) such as mountainous regions in the LCRB. For Western North America, these models are able to predict observed air temperature with a bias of $<2{ }^{\circ} \mathrm{C}$ (Hostetler et al. 2011), which is relatively good. We used one emissions scenario (i.e. AR4 A2; IPCC 2007; Hostetler et al. 2011) when constructing GCMs, which was selected because it represents higher levels of future emissions (850 ppm atmospheric $\mathrm{CO}_{2}$ in the year 2100; 2010 atmospheric $\mathrm{CO}_{2}=389 \mathrm{ppm}$ ) that would result in more pronounced climatic changes and subsequent range shifts. The emission scenario we chose falls between representative concentration pathways (RCP) 6.0 (670 ppm atmospheric $\mathrm{CO}_{2}$ in 2100) and 8.5 (936 ppm atmospheric $\mathrm{CO}_{2}$ in 2100) under the most current IPCC 5th assessment report (IPCC 2014). We did not investigate scenarios with less drastic $\mathrm{CO}_{2}$ increases because they would result in minimal climatic changes, presumably resulting in fish ranges remaining static under our modeling framework. If current $\mathrm{CO}_{2}$ emissions remain unchanged, the emissions scenario we chose is highly probable (IPCC 2014).

We used forecasted climate metrics to develop ENMs that predicted fish ranges following 75 years of climate change. For instance, forecasted temperature and precipitation metrics used as predictors in ENMs (i.e. mean annual air temperature and precipitation; $\mathrm{CV}$ of winter and spring precipitation) were averaged over a 30-year time period (2070-2099), which corresponded to the temporal span previously used to develop contemporary ENMs (Strecker et al. 2011). Climate metrics for 2070-2099 are represented as the midpoint of the time period (2085) in the remainder of this study. Values for this 30-year average of climate metrics were incorporated into ENMs to predict a new probability of occurrence for each fish species in each stream segment, while values of non-climatic predictor variables were left unchanged when predicting species future distributions. This modeling approach to forecasting range shifts assumes that climate change will influence fish distributions directly by altering temperatures and indirectly by influencing flow regimes (altered temperature and precipitation $=$ altered evapotranspiration, runoff, and flow). For instance, rising temperatures coupled with altered precipitation would predict that fishes should be shifting their distributions upslope to track their preferred thermal niche, so long as the altered precipitation of a segment allowed for a suitable flow regime for a given species. However, our environmental niche models do not include discharge, runoff, or evapotranspiration directly as predictors of fish distributions, as this information is not currently available for each stream segment in the LCRB. We acknowledge that using flow regime metrics (e.g., mean discharge, minimum discharge, zero-flow days, etc.), runoff, and evapotranspiration as direct predictors of fish distributions would have made for more biologically meaningful range estimates, but because of data limitations, we were left with flow proxies to forecast distributional changes. Regardless, because climate-induced changes in temperature and precipitation are among the most important reasons for altered flow in the coming decades (Jaeger et al. 2014), our climatic predictor variables should adequately forecast fish range shifts.

Fish range shifts were quantified according to changes in the leading and trailing edges of elevational 
ranges, elevational range center, and range size. Our range metrics focus on elevational rather than latitudinal descriptions of species ranges because anthropogenic and natural biogeographic barriers would prevent species from substantially shifting their latitudinal distributions. The leading and trailing edge of elevational ranges were defined as the maximum and minimum segment elevation, respectively, where a species was predicted to be present (i.e. probability of occurrence in a segment $\geq 0.50$; Strecker et al. 2011). Elevational range center was calculated as the average elevation across all segments where a species was predicted to be present, and range size was the number of occupied segments. Range shifts for each aspect of a species range were calculated by subtracting contemporary (2010) values from values in 2085. To examine the consistency between GCM predictions we performed correlations on the range shift predictions with species serving as replicates.

Range shifts and fish traits

We sought to investigate the ability of fish traits to explain forecasted range shifts. To accomplish this objective, seven competing models were developed to examine relationships among traits and climate-induced range shifts. Traits included characteristics describing a species origin (i.e. native or nonnative to the LCRB), conservation status, phylogeny, thermal tolerance, flow preference, dispersal ability, and establishment potential (Table 1). Conservation status was taken from the IUCN Red List (IUCN 2015), whereas other trait values were from Olden et al. (2006), and included a mixture of variables measured on nominal, ordinal, and continuous scales. All trait information compiled in Olden et al. (2006) were from studies within the LCRB or from geographically proximal locations, and as such should be representative of the species included in our analyses. Our trait database did not include direct estimates of dispersal ability, and as such, we used proxies that assumed larger body size (Radinger and Wolter 2013), larger shape factor (Webb and Weihs 1986), and smaller swim factor (Webb 1984) would result in greater dispersal ability. For each of the seven models, analyses began with an initial linear model that included all of the listed traits for a given model as predictor variables, and one of the four range shift metrics as a response variable. Continuous trait variables were Z-score transformed prior to analyses. For models that had a single predictor variable (i.e. the origin, conservation status, and phylogeny models), analyses ended there. For models with multiple traits, model selection was performed on the starting model to determine the traits most associated with range shifts. Model selection was accomplished using Akaike's Information Criterion corrected for small sample size $\left(\mathrm{AIC}_{\mathrm{c}}\right)$ to determine a final model that included the most parsimonious traits needed for explaining range shifts in a given model (Burnham and Anderson 2002). Final models for each of the seven competing models were then compared according to $\triangle \mathrm{AICc}$, statistical significance, and explanatory power (i.e. adjusted $\mathrm{R}^{2}$ ) to determine which trait(s) were most associated with range shifts, with the best model indicated by a $P<0.05$ and $\Delta \mathrm{AIC}_{\mathrm{c}}<2.0$. This model selection approach was completed for each of the four range shift metrics and two climate change scenarios $(2$ GCMs $\times 1$ emission scenario $\times 1$ time period $=2$ scenarios), resulting in 56 total models ( 7 competing models $\times 4$ range shift metrics $\times 2$ climate change scenarios $=56$ models). This analytic approach assumes that traits shape the present day distribution of species and will thus control the future distribution of species, which is a valid assumption given the prevailing effect of traits on stream fish distributions (Olden et al. 2006; Heino et al. 2013). We acknowledge that traits from different models may interact to influence range shifts (e.g., dispersal and establishment traits may interact to dictate shifts at the leading edge). However, our models did not include these interactions because we wanted to avoid model overparameterization by keeping the number of predictor variables to approximately 1/10th (i.e. four variables) of the sample size (i.e. 39 species) (Sunday et al. 2015). All linear models were created with the $R$ base package (R Core Team 2015).

\section{Similarity analyses}

We examined the similarity of the four range shift metrics using univariate and multivariate approaches. To examine the univariate similarity of the four range shift metrics among species we performed pairwise Pearson correlations between ranges shift metrics for each GCM. Significant positive correlations from this analysis would indicate two range metrics (e.g., the leading edge and range size) were shifting in a similar 
Table 1 Seven models developed to relate fish traits to predicted range shifts of fishes in the Lower Colorado River Basin in response to climate change

\begin{tabular}{|c|c|c|c|}
\hline Model & $\begin{array}{l}\text { Predictors } \\
\text { (abbreviation) }\end{array}$ & Values & $\begin{array}{l}\text { Variable } \\
\text { scale }\end{array}$ \\
\hline Origin & Origin & Native (Nat); Nonnative (NN) & Nominal \\
\hline Status & IUCN listing & $\begin{array}{l}\text { Nonnative (NN); Least concern(LC); Vulnerable (VU); Threatened (TH); } \\
\text { Endangered (EN); Critically-endangered (CE) }\end{array}$ & Nominal \\
\hline Phylogeny & Family or order & $\begin{array}{l}\text { Catostomidae (CAT); Cyprinidae (CYP); Cyprinodontiformes (CYPO); } \\
\text { Ictaluridae (ICT); Other (OTH); Salmonidae (SAL); Centrarchidae (CEN) }\end{array}$ & Nominal \\
\hline \multirow[t]{3}{*}{ Thermal } & $\begin{array}{l}\text { Critical thermal } \\
\text { maximum }(\mathrm{CTM})\end{array}$ & Low (L), Moderate (M), High (H), and Very high (VH) & Ordinal \\
\hline & $\begin{array}{l}\text { Temperature } \\
\text { preference }(\mathrm{TP})\end{array}$ & Cold- (CDW), Cool- (CW), and Warmwater (WM) & Ordinal \\
\hline & $\begin{array}{l}\text { Spawning } \\
\text { temperature (ST) }\end{array}$ & Temperature at which spawning is typically initiated $\left({ }^{\circ} \mathrm{C}\right)$ & Continuous \\
\hline \multirow[t]{2}{*}{ Flow } & $\begin{array}{l}\text { Fluvial dependence } \\
\text { (FD) }\end{array}$ & Yes; No & Nominal \\
\hline & $\begin{array}{l}\text { Current preference } \\
\text { (CP) }\end{array}$ & Slow (S); Slow-moderate (SM); moderate (M); Moderate-fast (MF); Fast (F) & Ordinal \\
\hline \multirow[t]{3}{*}{ Dispersal } & $\begin{array}{l}\text { Maximum body } \\
\text { length }(\mathrm{MBL})\end{array}$ & Total body length $(\mathrm{cm})$ & Continuous \\
\hline & Shape factor (SHF) & Total body length: Maximum body depth & Continuous \\
\hline & Swim factor (SWF) & Minimum depth caudal peduncle: Maximum depth caudal fin & Continuous \\
\hline \multirow[t]{4}{*}{ Establishment } & Trophic guild (TG) & $\begin{array}{l}\text { Herbivore-detritivore (HD); Omnivore (OMN); Invertivore (INV); Invertivore- } \\
\text { piscivore (INVP); Piscivore (PISC) }\end{array}$ & Nominal \\
\hline & Diet breadth (DB) & Number of diet items consumed; range $2-6$ & Ordinal \\
\hline & Fecundity (FEC) & Number of eggs or offspring per breeding season & Continuous \\
\hline & $\begin{array}{l}\text { Reproductive guild } \\
\text { (RG) }\end{array}$ & $\begin{array}{l}\text { Nonguarder (open substratum [NG_OS] or brood hider [NG_BH]); Guarder } \\
\text { (substratum chooser }\left[\mathrm{G} \_S C\right] \text {; nest spawner [G_NS]); Bearer (external [B_E]) }\end{array}$ & Nominal \\
\hline
\end{tabular}

Predictor variables used in each model along with their values and scale of measurement are also indicated. All traits values except status are from Olden et al. (2006); status was taken from IUCN (2015)

manner. The multivariate similarity of range metrics with regards to fish traits was analyzed using redundancy analysis (RDA). Redundancy analysis relates multiple predictor variables (i.e. fish traits) to multiple response variables (i.e. four range shift metrics) using Euclidean distance matrices (van dan Wollenberg 1977). For each of the two climate scenarios we created a species $\times$ range shift matrix (i.e. 39 species $\times 4$ range shift metrics). The species $\times$ range shift matrix was then related to a global species $\times$ trait predictor matrix (i.e. 39 species $\times 15$ traits) using RDA on a correlation matrix. We chose a correlation rather than covariance matrix for RDA input because range size (change in number of segments) was measured on a different scale than the other three metrics (change in elevation). A forward selection procedure was then used to select the traits that could most parsimoniously explain the multivariate range response, with significant traits retained in a final RDA model. The significance of the final RDA model and model axes was assessed using analysis of variance (ANOVA). The explanatory power of the final RDA model was assessed using an adjusted $\mathrm{R}^{2}$. If the final RDA analysis was not significant for a scenario, principal components analysis (PCA), which is the unconstrained (i.e. lacking predictor variables) version of RDA, was performed on the correlation matrix of range shifts. All multivariate analyses were performed using functions from the vegan R library (Oksanen et al. 2015). 


\section{Results}

Climatic variables were among the most important predictors of fish distributions in the LCRB. For instance, mean annual air temperature and precipitation had a significant effect in 85 and $82 \%$, respectively, of ENMs, trailing only elevation $(90 \%$ of ENMs) in terms of overall importance in describing contemporary fish ranges (Online Resource 3). However, coefficient of variation in winter and spring precipitation were of less importance, significantly predicting distributions in only 56 and $31 \%$ of ENMs, respectively. Models performed well in predicting contemporary species ranges, as all 39 ENMs (i.e. 18 native ENMs, 21 nonnative ENMs) had an AUC $>0.75$ (Online Resource 3).

Climate-induced range shifts

Climate forecasts indicated increasing temperature and precipitation in the LCRB, although the overall magnitude of change differed somewhat between models. Mean annual air temperature across the LCRB in 2085 increased by 25 and $17 \%$ under the ECHAM5 and GENMOM scenarios, respectively (Table 2). Changes in mean annual precipitation were less pronounced, with ECHAM5 (8\%) and GENMOM (4\%) both predicting greater precipitation. The coefficient of winter and spring precipitation varied little under climate change scenarios.

In response to forecasted climatic changes in 2085, an average of $58 \%$ of species shifted the leading edge of their distribution upslope while, on average, $70 \%$ of species shifted the trailing edge of their distribution downslope (averaged across GCMs). The magnitude of change was much greater for the leading edge (mean increase of $127 \mathrm{~m}$ ) relative to the trailing edge (mean increase of $4.5 \mathrm{~m}$ ), however, resulting in $57 \%$ of species shifting their range center upslope. The predominance and greater magnitude of upslope shifts at the leading edge was expected given the predicted increases in mean annual temperature between 2010 and 2085 (Table 2). Shifts in range limits resulted in a net increase in range size for $44 \%$ of species (Table 3 ; Online Resources 4 and 5). For most species, an upslope shift at the leading edge coupled with a downslope shift at the trailing edge resulted in an increase in range size, but this was not necessarily the case for all species (e.g., Catostomus latipinnis [flannelmouth sucker]) (Online Resource 5). Further, for some species substantial changes in range size could occur even if there were minimal changes in range limits (e.g., Rhinichthys osculus [speckled dace]). Regardless, because climate forecasts were similar between GCMs, range shifts were generally similar between scenarios, with significant relationships between predicted changes for the leading edge $\left(\mathrm{F}_{1,38}=22.8 ; \quad P<0.01 ; \quad \mathrm{r}=0.62\right.$, trailing edge $\left(\mathrm{F}_{1,38}=360.5 ; \quad P<0.01 ; \mathrm{r}=0.95\right)$, range center $\left(\mathrm{F}_{1,38}=83.0 ; P<0.01 ; \mathrm{r}=0.83\right)$, and range size $\left(\mathrm{F}_{1,38}=212.2 ; P<0.01 ; \mathrm{r}=0.92\right)$.

Range shifts and fish traits

The traits we predicted to influence range shifts were confirmed for the leading edge, but predictions were not realized for other range shift metrics. For instance, our prediction that traits related to establishment potential would best predict shifts at the leading edge of species ranges was confirmed for GENMOM, although no traits predicted shifts at the leading edge under ECHAM5 (Table 4). Greater diet breadth
Table 2 Current (2010) and projected (2070-2099; midpoint $=2085$ ) temperature and precipitation metrics averaged across stream segments in the Lower Colorado River Basin,
USA under two general circulation models (ECHAM5 and GENMOM) and the AR4 A2 emissions scenario

\begin{tabular}{llll}
\hline Climate variable & Current & ECHAM5 & GENMOM \\
\hline Mean annual air temperature $\left({ }^{\circ} \mathrm{C}\right)$ & 13.9 & 17.4 & 16.3 \\
Mean annual precipitation $(\mathrm{mm})$ & 196 & 212 & 204 \\
$\mathrm{CV}$ winter precipitation & 0.15 & 0.15 & 0.15 \\
$\mathrm{CV}$ spring precipitation & 0.35 & 0.36 & 0.35 \\
\hline
\end{tabular}

$C V$ coefficient of variation 
Table 3 Summary of range shifts of Lower Colorado River Basin fishes in response to forecasted climate change

\begin{tabular}{|c|c|c|c|c|c|}
\hline GCM & Metric (units) & Mean change $(\%)$ & Min change (Spp.) & Max change (Spp.) & $\begin{array}{l}\text { \# (\%) Spp. } \\
\text { increasing }\end{array}$ \\
\hline \multirow[t]{4}{*}{ ECHAM5 } & Leading edge (m) & $132(5)$ & -782 (red shiner) & 1089 (Colorado pikeminnow) & $21(54)$ \\
\hline & Trailing edge $(\mathrm{m})$ & $3(1)$ & -1504 (golden shiner) & 1402 (Colorado pikeminnow) & $12(31)$ \\
\hline & Range center (m) & $-17(-1)$ & -899 (brown trout) & 1016 (Colorado pikeminnow) & $21(54)$ \\
\hline & Range size (segments) & $595(13)$ & $-11,599$ (speckled dace) & 11,971 (flathead catfish) & $18(46)$ \\
\hline \multirow[t]{4}{*}{ GENMOM } & Leading edge $(\mathrm{m})$ & $121(5)$ & -370 (loach minnow) & 616 (smallmouth bass) & $23(59)$ \\
\hline & Trailing edge (m) & $6(2)$ & -1357 (golden shiner) & 1475 (Colorado pikeminnow) & $13(33)$ \\
\hline & Range center (m) & $19(2)$ & -820 (brown trout) & 935 (bluegill) & $24(62)$ \\
\hline & Range size (segments) & $-70(-1.5)$ & -9195 (speckled dace) & 7901 (flathead catfish) & $16(41)$ \\
\hline
\end{tabular}

Range shifts are summarized for two general circulation models (GCMs) in 2085 according to the mean, minimum, and maximum change across 39 species, as well as the number of species increasing the value of a particular metric. Range metrics include the leading edge (maximum segment elevation where a species is present; present $=$ probability of occurrence $\geq 0.50$ ), trailing edge (minimum segment elevation where a species is present), range center (mean segment elevation where a species is present), and range size (number of occupied segments). Nonnative species are in bold

Table 4 Top models explaining range shifts according to fish traits

\begin{tabular}{llllll}
\hline GCM & Response & Prediction & Top model & Significant trait(s) & Adjusted R $^{2}$ \\
\hline ECHAM5 & Leading edge & Establishment & Intercept & - & - \\
& Trailing edge & Thermal & Dispersal & MBL(+); SHF(+) & 0.17 \\
& Range center & - & Intercept & - & - \\
& Range size & - & Intercept & - & - \\
GENMOM & Leading edge & Establishment & Establishment & TG (OMN $\uparrow$ PISC $\uparrow) ;$ DB $(+)$ & 0.30 \\
& Trailing edge & Thermal & Dispersal & MBL(+); SHF(+) & 0.18 \\
& Range center & - & Intercept & - & - \\
& Range size & - & Intercept & - & - \\
\hline
\end{tabular}

Range shifts included changes in the leading edge (maximum elevation; $\mathrm{m}$ ), trailing edge (minimum elevation; $\mathrm{m}$ ), range center (mean elevation; m) and range size (number of occupied segments) of fishes in the Lower Colorado River Basin between current values and those forecasted in 2085 using the ECHAM5 and GENMOM general circulation models (GCMs). Significant traits included in the top model are indicated. All top models that included traits had a $P<0.05$ and $\triangle \mathrm{AICc}=0.0$ for each range response metric. The slope $(+$ or - ) of the relationship is indicated in parentheses for continuous predictor variables, and for nominal or ordinal predictor variables, categories resulting in the largest range increase are indicated

$D B$ diet breadth; $M B L$ maximum body length; OMN omnivore; PISC piscivore; SHF shape factor; TG trophic guild

promoted increases in maximum elevation, and omnivores and piscivores increased the maximum elevation of their range more than other trophic guilds (Table 4). By contrast, invertivorous fishes with more specialized diets exhibited minimal changes in the maximum elevation of their range. Traits describing thermal tolerance were not related to shifts at the trailing edge under any climate scenario, contradicting our initial predictions. Instead, the dispersal model was best under both GCMs, with maximum body length and shape factor positively associated with upstream shifts in the minimum elevation of species ranges, with less mobile fishes exhibiting less pronounced changes. Finally, despite the influence of traits on shifts at the leading and trailing edges, no traits were associated with shifts in the mean elevation or size of species ranges regardless of climate scenario. 
Similarity of univariate and multivariate ranges shifts

Changes at the trailing edge and range center were the most highly correlated range shift metrics within ECHAM5 $(r=0.54)$ and GENMOM $(r=0.53)$, suggesting species were shifting the trailing edge and center of their ranges to a similar, albeit small, degree (Table 3; Online Resource 6). However, RDA revealed that traits were not associated with multivariate range shifts (i.e., all four range shift metrics examined simultaneously) under the ECHAM5 scenario. Visualization of multivariate range responses under ECHAM5 using a PCA biplot revealed several species pairs exhibiting similar multivariate range shifts, including Salmo trutta (brown trout) and Pantosteus clarkii (desert sucker), as well as Oncorhynchus mykiss (rainbow trout) and Rhinichthys cobitis (loach minnow) (Fig. 2). However, the similarity of these responses occurred independent of the traits examined (i.e. idiosyncratic responses). The similarity of multivariate range shifts among species under the GENMOM scenario was best explained by current preference $\left(\mathrm{F}_{1,37}=2.9 ; P=0.03\right)$, although explanatory power was low $\left(\mathrm{R}^{2}=0.05\right)$. Fishes with faster current preference (e.g., R. osculus; R. cobitis) exhibited smaller multivariate range shifts relative to species with slower current preferences (e.g., Colorado pikeminnow [Ptychocheilus lucius]; razorback sucker [Xyrauchen texanus]) (Fig. 2).

\section{Discussion}

We found that temperature and precipitation will increase throughout the LCRB by the year 2085 , which could influence fish distributions directly by altering thermal niche availability and indirectly by altering flow regimes. These climatic changes forecasted by our study would predict fishes shifting their distributions upslope to track their preferred thermal niche, so long as the altered precipitation of a segment allowed for a suitable flow regime for a given species. Many species conformed to these expectations, with a majority of species shifting the leading edge of their distribution upslope by a magnitude greater than the change at the trailing edge and range center. Changes in range limits resulted in greater range size for approximately half of species, whereas the other half exhibited range reductions. The combined influence of range expansions of some species coupled with range contractions by others will present challenges for native and nonnative fish management in the LCRB. Anticipating these challenges will be difficult, but our results indicated that traits have utility in forecasting climate-induced range shifts.

Trophic traits were most associated with shifts at the leading edge, although conclusions differed between GCMs. For instance, diet breadth had a positive relationship with elevational change, and omnivores and piscivores exhibited larger shifts than other trophic guilds under the GENMOM scenario. By contrast, these trophic traits had no ability to predict range shifts under the ECHAM5 scenario. Trait-range shift relationships agreed between GCMs for all other range shift metrics. The discrepancy in conclusions between ECHAM5 and GENMOM in explaining shifts at the leading edge was likely a consequence of two factors. First, ECHAM5 predicted greater increases in temperature and precipitation relative to GENMOM. Second, the leading edge is generally more sensitive to climate change than other range metrics, as colonization at the leading edge is more rapid than extinction at the trailing edge (Hampe and Petit 2005). As such, because ECHAM5 predicted a larger magnitude increase in temperature, it also resulted in greater shifts at the leading edge relative to GENMOM, resulting in different modeling results when examining the influence of traits on range shifts.

The relationships we identified between range shifts and trophic traits were in agreement with previous studies. For instance, the positive influence of diet breadth on shifts at the leading edge under GENMOM concurs with Sunday et al. (2015), who found a positive relationship between range size and documented range shifts of some marine fishes, presumably because species with broader ranges have broader diets and niches. In addition to diet breadth, our study also identified omnivory as a facilitator of expansion at the leading edge, agreeing with previous studies that hypothesized species with generalist trophic strategies should exhibit range expansions under climate change, as a generalized diet promotes colonization (Stoll et al. 2014; Sunday et al. 2015; Estrada et al. 2016). Further, our conclusion that piscivory had a positive influence on shifts at the leading edge were in accord with those from Comte et al. (2014), who found piscivores experienced the 
Fig. 2 Multivariate range shifts in the leading edge, trailing edge, center, and size visualized using a principal component (PC) analysis biplot for ECHAM5 or a redundancy analysis triplot (RDA) with current preference as a predictor variable for GENMOM. Because there was only one significant predictor variable in the RDA for GENMOM, only the first axis (RDA 1) is an RDA axis, whereas the second axis (PC1) is calculated using unconstrained PCA. The amount of variation explained by each axis is also indicated. For each plot, the more closely positioned are two species in multivariate space, the more similar is their multivariate range shift. See Online Resource 2 for species codes
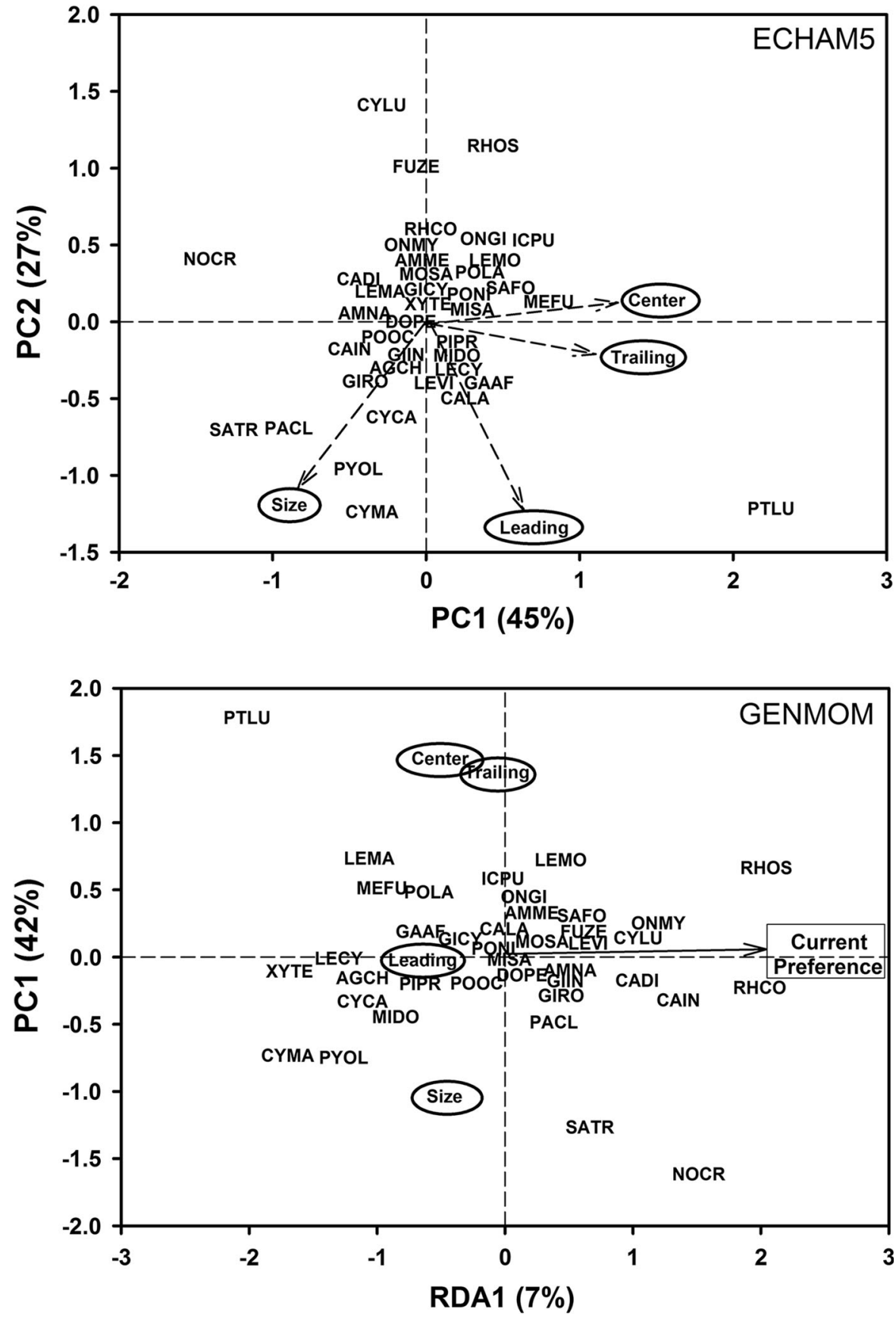

greatest upslope shifts at the leading edge of distributions in French streams.

The positive influence of piscivory on shifts at the leading edge may result in several 'winners' under a changing climate (Somero 2010). For instance, Salmo trutta and Pylodictis olivaris (flathead catfish) were two of the fishes that increased in occurrence most following climate change (Online Resource 5). These two climate 'winners' are nonnative piscivores (Pilger et al. 2010) and have been associated with native fish declines in Colorado River Basin streams (Whitney et al. 2014), thus their climate-mediated spread and concomitant alteration of biotic interactions may have deleterious consequences for long-term native fish 
conservation (Cahill et al. 2012). Native fish imperilment resulting from climate-induced spread of nonnative piscivores has been predicted elsewhere (Jackson and Mandrak 2002), and deserves further attention in the LCRB. The influence of trophic traits on range shifts suggests that climate change could have profound effects on food web structure in the LCRB (Ficke et al. 2007; Shurin et al. 2012; Seifert et al. 2015), but further study is needed to address how climate change will alter trophic relationships (Comte et al. 2013).

We found that invertivorous fishes with more specialized diets exhibited minimal changes in the leading edge of their range, potentially because their food became less prevalent under novel climate, or the generally small body size exhibited by this functional group limited their ability to disperse (Olden et al. 2006). We did not model changes in food availability and therefore cannot evaluate the first possibility, but small-bodied species did exhibit smaller shifts at the trailing edge in our study, lending support to the second hypothesis. It may be that body size interacts with diet to influence range shifts (e.g., small-bodied species with general diets shift more than smallbodied species with specialized diets), but our models could not account for interactions among multiple trait categories because of the small number of species included relative to the number of traits examined. Future studies that include more species should investigate the influence of trait interactions on range shifts. Regardless, the inability of invertivorous fishes with narrow diets to shift the leading edge of their distribution upslope indicates that this functional group may require greater management intervention (e.g. assisted dispersal; Lawler and Olden 2011) to ensure their range shifts can keep pace with the velocity of climate change (Loarie et al. 2009).

Traits related to dispersal explained shifts at the trailing edge of species ranges. For instance, maximum body length and shape factor exhibited positive relationships with range shifts at the trailing edge, with both traits suggesting increasing dispersal ability resulted in greater upslope range shifts (Webb and Weihs 1986; Radinger and Wolter 2013). In agreement with these results, Comte et al. (2014) also found a weak, albeit significant, relationship between mobility and range shifts for stream fishes. On the other hand, small-bodied marine fishes with presumably lower dispersal propensity exhibited the greatest distributional shifts in response to climate change (Perry et al. 2005). The discrepancy between our results and those of Perry et al. (2005) are likely attributable to the greater connectivity of marine habitats compared to our xeric riverscape (Ward et al. 1994). Similar to specialized invertivores, fishes with lower dispersal ability may require greater management to maintain their ranges under climate change.

Current preference explained a small amount of variation in multivariate range shifts under the GENMOM scenario, as species with faster current preferences shifted their multivariate ranges less than species with slower current preferences. This result may be related to our GCM forecasts of $17-25 \%$ warmer temperatures coupled with $4-8 \%$ increases in precipitation by 2085 . The slightly greater precipitation predicted for 2085 may not compensate for the greater evapotranspiration arising from higher air temperatures, causing increasing aridity, less runoff, and ultimately lower discharge. As such, under these drier conditions there may be a lack of suitable flowing-water habitat for species with faster current preferences to relocate to, thus explaining their smaller multivariate range shifts relative to fishes with slower current preferences. However, we did not forecast changes in evapotranspiration, runoff, or discharge directly, and as such can only speculate that the lower magnitude range shifts of fishes preferring faster currents was due to changes in flow. Future studies should estimate and incorporate evapotranspiration and discharge directly to predict fish range shifts in response to climate change for the entire LCRB, as has been done previously at finer spatial scales (Jaeger et al. 2014). Our climate forecasts are in agreement with previous climate modeling studies in the region that, in addition to temperature and precipitation, investigated changes in runoff, evapotranspiration, and/or discharge (Christensen and Lettenmaier 2007; Seager et al. 2013; Jaeger et al. 2014); all of these studies predicted increasing aridity in the region. The ongoing "lentification" of the LCRB is contributing to the imperilment of fishes preferring flowing water (Ruhi et al. 2016), and our results indicated that this problem may get worse with climate change. Management actions that help to keep water in the channel (e.g., decreased surface water and groundwater withdrawals) may help in conserving fishes with faster current preferences under climate change, although this management strategy will be 
difficult given the projected increase in human population size for the region (Gober and Kirkwood 2010; Marshall et al. 2010).

Although certain trophic, dispersal, and habitat preference traits predicted changes for some range metrics, forecasted range shifts in response to climate change were largely unrelated to the traits examined. For instance, origin and conservation status of fishes were generally uninformative in predicting range shifts across climate change scenarios. Highly dissimilar traits can result in equivalent levels of imperilment of natives or invasion success of nonnatives, because different processes cause population size to change (Olden et al. 2006, 2008). As such, the lack of relationship between conservation status and origin with range shifts is not entirely surprising. The idiosyncrasy of native and nonnative range shifts could make coping with climate change difficult, as management strategies necessary to deal with climate change effects on LCRB fishes may need to be tailored according to each species needs (Angert et al. 2011). However, no effect of origin and imperilment status on range shifts could be viewed as an encouraging result for native fish conservation and nonnative management, as we found that imperiled species were no more likely to decline than were stable species, and nonnative species were no more likely to expand than were natives (Table 5). Given that imperiled species are frequently predicted to exhibit range decreases under a changing climate (Xenopoulos et al. 2005) while nonnatives are expected to show range increases (Rahel and Olden 2008), our results indicated that the climatically-altered future may not be as bleak for fish conservation as is oftentimes predicted. However, warming temperatures may promote the invasion of novel nonnative fishes currently unable to establish populations in the LCRB because of high critical thermal minima (e.g., tropical fishes), which our study did not consider (Bennett et al. 1997; Rahel and Olden 2008). Furthermore, the presence of other anthropogenic stressors besides climate change will likely continue to imperil fishes in the LCRB (Ruhi et al. 2016), and may interact with climate change in ways we did not account for to produce native range contractions and nonnative range expansions. For instance, our models did not account for greater water extraction in the LCRB because of growing human populations (Gober and Kirkwood 2010; Marshall et al. 2010), which could compound the problems associated with increased aridity beyond those presently forecasted. Long-term monitoring will be required to document the actual effects of climate change on fish ranges to assess the validity of our predictions.

Range shifts were unrelated to most traits examined, suggesting the fish response to climate change is largely species-specific. Similarly, Buisson et al. (2008) found that forecasted range shifts of stream fishes in France were predominantly idiosyncratic, although thermal guild demonstrated some ability to explain climate-induced range shifts. The lack of association between fish traits and range shifts was surprising for several traits that have been associated with range shifts elsewhere. For instance, life history traits related to propagule supply (e.g. fecundity, parental care) have been implicated in range shifts for stream fishes (Comte et al. 2014) and marine fishes (Perry et al. 2005), yet life history traits were unrelated to range shifts in our study. The difference between ours and previous studies with regards to life history effects on range shifts may be a consequence of our study looking at forecasted range shifts, whereas the previously mentioned studies examined documented range shifts. Furthermore, taxonomic (phylogenetic) relatedness was identified as a primary determinant of observed range contractions of French stream fishes by Comte et al. (2014), largely because of low thermal tolerance possessed by members of the family Salmonidae (Chu et al. 2005; Comte et al. 2013; Kovach et al. 2016). By contrast, neither taxonomy nor thermal tolerance predicted range shifts under either GCM, with the four salmonid species included in our study exhibiting a variety of responses across scenarios despite models consistently predicting long-term temperature increases. The lack of association between range shifts and taxonomic relatedness or thermal tolerance may be because other environmental variables included in ENMs had a dampening effect on temperature-mediated range shifts (Buisson et al. 2008). This seems unlikely however, given the predominant importance of temperature relative to other variables in predicting species occurrences (Online Resource 3). Had the magnitude of air temperature increase been greater than that predicted by our GCMs, taxonomic relatedness and thermal guild may have made a more significant contribution to explaining climate-mediated range shifts. 
Table 5 Mean of range shifts of fishes in the Lower Colorado River Basin according to origin and IUCN listing for two general circulation models (GCMs) in 2085

\begin{tabular}{|c|c|c|c|c|c|c|c|c|}
\hline \multirow[t]{2}{*}{ GCM } & \multirow[t]{2}{*}{ Range metric } & \multicolumn{2}{|l|}{ Origin } & \multicolumn{5}{|l|}{ Imperilment } \\
\hline & & Native & Nonnative & Least concern & Vulnerable & Threatened & Endangered & Critically endangered \\
\hline \multirow[t]{4}{*}{ ECHAM5 } & Leading edge & 205 & 70 & 179 & 390 & 312 & 147 & 9 \\
\hline & Trailing edge & 85 & -68 & -119 & 522 & -164 & 39 & 66 \\
\hline & Range center & -13 & -21 & -214 & 132 & -335 & 114 & 148 \\
\hline & Range size & 582 & 606 & 189 & 385 & 2636 & 1367 & -833 \\
\hline \multirow[t]{4}{*}{ GENMOM } & Leading edge & 120 & 122 & 127 & 111 & 76 & 65 & 274 \\
\hline & Trailing edge & 68 & -47 & -93 & 424 & -164 & 25 & 66 \\
\hline & Range center & 21 & 16 & -134 & 112 & -162 & 120 & 150 \\
\hline & Range size & -451 & 256 & -2059 & 321 & 328 & 565 & -99 \\
\hline
\end{tabular}

Units are in meters for the leading edge (change in maximum elevation of range), trailing edge (change in minimum elevation of range), and range center (change in mean elevation of range), whereas change in range size is measured according to the change in number of occupied stream segments

The limited influence of traits on predicted ranges shifts may have been the result of data constraints. Our analysis assumed that traits shape contemporary distributions, which may be incorrect if mass effects (Shmida and Wilson 1985; Leibold et al. 2004), dispersal limitation (Heino et al. 2015), and/or imperfect detection (MacKenzie et al. 2002) are present in our fish occurrence database. All of these factors operate to obscure present-day relationships among fish, their traits, and preferred environmental conditions, which could propagate through our projections to limit relationships between traits and range shifts. Greater screening of the fish database to separate occurrences in anomalous locations from those in preferred environmental conditions could ameliorate this problem. This task will be a challenging endeavor, but could provide insight into the effect of traits on current distributions, which would thus help in predicting future distributions under climate change.

In addition to the caveats mentioned in the previous paragraph, it is important to mention several other considerations when interpreting the results of our study. First, we assumed that fish colonized stream segments if changes in temperature and precipitation metrics resulted in more favorable environmental conditions, and that suitable segments were readily colonized by fish species; this assumption may be inappropriate if dispersal limitation is present (Fukushima et al. 2007; Buisson et al. 2008). For instance, upslope movements may be less than predicted if stream size prevents colonization, although our analyses partially controlled for a stream size effect by incorporating stream size metrics (i.e. gradient; elevation). Second, we may have overestimated elevational range shifts within river basins by not accounting for fragmentation arising from impoundments and dewatering, which are widespread throughout the LCRB and are predicted to become even more prevalent with climate change (Jaeger et al. 2014). Lastly, other environmental variables included in our analyses (e.g. the percent agricultural and urban land area in a watershed) will likely change through time and influence fish ranges, although all nonclimatic predictor variables remained constant in our analyses. However, given the predominant importance of climatic and invariant predictors (e.g. elevation) in predicting species ranges (Online Resource 3), the importance of other variables likely to change in the coming decades (e.g. percent agricultural and urban land area in a watershed) may be of less consequence. By not accounting for dispersal limitation, fragmentation, and water/land use change, the realized shifts in elevational limits, elevational center, and range size may differ from those reported here. Future projections that forecast distributional shifts while accounting for fragmentation (Hein et al. 2011; Melles et al. 2015), water extraction, and changes in land use could help refine range shift predictions for LCRB fishes. 


\section{Conclusion}

Our results quantified multiple range shift metrics, and as identified by the low to moderate correlations between range shift metrics (all $\mathrm{r} \leq 0.54$; Online Resource 6), revealed that investigation of each range metric provided unique information. As such, investigating multiple range metrics provided a more complete picture of climate-induced range shifts compared to investigating a single metric alone (Comte et al. 2014). Further, our results are among the first to forecast climate-mediated range shifts in an arid-land river system containing a community largely comprised of imperiled and nonnative fishes. We found that climate-mediated range shifts were unrelated to most traits, although certain trophic (trophic guild, diet breadth), dispersal (shape factor, maximum body length), and habitat preference characteristics (current preference) provided some predictive capability in describing univariate or multivariate range shifts. The presence of individualistic responses indicated that development of generalized climate adaptation strategies will be challenging, suggesting conservation and management plans may have to be tailored according to each species response to ensure that 'losers' in a changing climate are not entirely lost.

Acknowledgements We thank the U.S. National Aquatic Gap Analysis Program, the U.S. National Climate Change and Wildlife Sciences Center, and the U.S. Fish and Wildlife Service for funding provided to complete this project. The fish occurrence database used for this research reflects countless hours of field research and data organization by stakeholders who provided their datasets. In particular, we owe a debt of gratitude to Arizona Game and Fish Department, Arizona Natural Heritage Program, New Mexico Environment Department, Utah Natural Heritage Program, Nevada Department of Wildlife, Museum of Southwestern Biology at the University of New Mexico, Arizona State University, and Arizona Cooperative Fish and Wildlife Research Unit for sharing their datasets. Previous versions of this manuscript benefitted from insightful comments by Dan Dauwalter of Trout Unlimited, Jane Fencl of the University of Washington, the Missouri Cooperative Fisheries and Wildlife Research Unit Aquatic Sciences Journal Club, Colleen Caldwell of New Mexico State University, Janine Powell of the U.S. Geological Survey, three anonymous reviewers, and the journal editors. Any use of trade, firm, or product names is for descriptive purposes only and does not imply endorsement by the U.S. Government or other sponsoring or participating agencies. The Missouri Cooperative Fish and Wildlife Research Unit is sponsored by the Missouri Department of Conservation, the University of Missouri, the U.S. Fish and Wildlife Service, the U.S. Geological Survey, and the Wildlife Management Institute.

\section{References}

Alder JR, Hostetler SW, Pollard D, Schmittner A (2011) Evaluation of a present-day climate simulation with a new coupled atmosphere-ocean model GENMOM. Geosci Model Dev 4:69-83

Angert AL, Crozier LG, Rissler LJ, Gilman SE, Tewksbury JJ, Chunco AJ (2011) Do species' traits predict recent shifts at expanding range edges? Ecol Lett 14:677-689

Bates AE, Pecl GT, Frusher S, Hobday AJ, Wernberg T, Smale DA, Sunday JM, Hill NA, Dulvy NK, Colwell RK, Holbrook NJ, Fulton EA, Slawinski D, Feng M, Edgar GJ, Radford BT, Thompson PA, Watson RA (2014) Defining and observing stages of climate-mediated range shifts in marine systems. Glob Environ Change 26:27-38

Bennett WA, Currie RJ, Wagner PF, Beitinger TL (1997) Cold tolerance and potential overwintering of the Red-Bellied Piranha (Pygocentrus nattereri) in the United States. Trans Am Fish Soc 126:841-849

Buckley LB (2012) Functional and phylogenetic approaches to forecasting species' responses to climate change. Annu Rev Ecol Evol Syst 43:205-226

Buckley LB, Tewksbury JJ, Deutsch CA (2013) Can terrestrial ectotherms escape the heat of climate change by moving? Proc R Soc Lond B Biol Sci 280:20131149

Buisson L, Thuiller W, Lek S, Lim P, Grenouillet G (2008) Climate change hastens the turnover of stream fish assemblages. Glob Change Biol 14:2232-2248

Burnham KP, Anderson DR (2002) Model selection and multimodel inference: a practical information theoretic approach, 2nd edn. Springer, New York

Cahill AE, Aiello-Lammens ME, Fisher-Reid MC, Hua X, Karanewsky CJ, Ryu HY, Sbeglia GC, Spagnolo F, Waldron JB, Warsi O, Wiens JJ (2012) How does climate change cause extinction? Proc R Soc Lond B Biol Sci 280:20121890

Carlson CA, Muth RT (1989) The Colorado River: lifeline of the American Southwest. In: Proceedings of the international large river symposium, vol 106. Canadian Special Publication of Fisheries and Aquatic Science, pp 220-239

Christensen N, Lettenmaier DP (2007) A multi-model ensemble approach to assessment of climate change impacts on the hydrology and water resources of the Colorado River basin. Hydrol Earth Syst Sci 3:1-44

Chu C, Mandrak N, Minns CK (2005) Potential impacts of climate change on the distributions of several common and rare freshwater fishes in Canada. Divers Distrib 11:299-310

Comte L, Buisson L, Daufresne M, Grenouillet G (2013) Climate-induced changes in the distribution of freshwater fish: observed and predicted trends. Freshw Biol 58:625-639

Comte L, Murienne J, Grenouillet G (2014) Species traits and phylogenetic conservatism of climate-induced range shifts in stream fishes. Nat Commun 5:5023

Crimmins SM, Dobrowski SZ, Greenberg JA, Abatzoglou JT, Mynsberge AR (2011) Change in climate water balance drive downhill shifts in plant species optimum elevations. Science 331:324-327

Elith J, Graham CH, Anderson RP, Dudík M, Ferrier S, Guisan A, Hijmans RJ, Huettmann F, Leathwick JR, Leahmann A, 
Li J, Lohman LG, Loiselle BA, Manion G, Moritz C, Nakamura M, Nakazawa Y, McC OJ, Peterson AT, Phillips SJ, Richardson KS, Scachetti-Pereira R, Schapire RE, Soberón J, Williams S, Wisz MS, Zimmermann NE (2006) Novel methods improve prediction of species' distributions from occurrence data. Ecography 29:129-151

Elith J, Kearney M, Phillips S (2010) The art of modelling range-shifting species. Methods Ecol Evol 1:330-342

Estrada A, Morales-Castilla I, Caplat P, Early R (2016) Usefulness of species traits in predicting range shifts. Trends Ecol Evol 31:190-203

Ficke AD, Myrick CA, Hansen LJ (2007) Potential impacts of global climate change on freshwater fisheries. Rev Fish Biol Fish 17:581-613

Fielding AH, Bell JF (1997) A review of methods for the assessment of prediction errors in conservation presence/ absence models. Environ Conserv 24:38-49

Friedman JH (1991) Multivariate adaptive regression splines. Ann Stat 19:1-67

Fukushima M, Kameyama S, Kaneko M, Nakao K, Steel EA (2007) Modelling the effects of dams on freshwater fish distributions in Hokkaido, Japan. Freshw Biol 52:1511-1524

Gober P, Kirkwood CW (2010) Vulnerability assessment of climate-induced water shortage in Phoenix. Proc Nat Acad Sci USA 107:21295-21299

Guisan A, Thuiller W (2005) Predicting species distribution: offering more than just simple habitat models. Ecol Lett 8:993-1009

Hampe A, Petit RJ (2005) Conserving biodiversity under climate change: the rear edge matters. Ecol Lett 8:461-467

Hastie T, Tibshirani RJ (1996) Discriminant analysis by Gaussian mixtures. J Roy Stat Soc B 58:155-176

Hein C, Öhlund G, Englund G (2011) Dispersal through stream networks: modelling climate-driven range expansion of fishes. Divers Distrib 17:641-651

Heino J, Schmera D, Erös T (2013) A macroecological perspective of trait patterns in stream communities. Freshw Biol 58:1539-1551

Heino J, Melo AS, Siqueira T, Soininen J, Valanko S, Bini LM (2015) Metacommunity organization, spatial extent, and dispersal in aquatic systems: patterns, processes, and prospects. Freshw Biol 60:845-869

Hickling R, Roy DB, Hill JK, Fox R, Thomas CD (2006) The distributions of a wide range of taxonomic groups are expanding polewards. Glob Change Biol 12:450-455

Hostetler SW, Alder JR, Allan AM (2011) Dynamically downscaled climate simulations over North America: methods, evaluation and supporting documentation for users. U.S. Geological Survey Open-File Report 2011-1238, p 64

Huey RB, Kearney MR, Krockenberger A, Holtum JAM, Jess M, Williams SE (2012) Predicting organismal vulnerability to climate warming: roles of behavior, physiology, and adaptation. Philos Trans R Soc Lond B Biol Sci 367:1665-1679

Intergovernmental Panel on Climate Change (2007) Climate change 2007: impacts, adaptations and vulnerability. Cambridge University Press, Cambridge

Intergovernmental Panel on Climate Change (2014) Climate change 2014: impacts, adaptations, and vulnerability. Cambridge University Press, Cambridge
International Union for the Conservation of Nature (2015) IUCN red list of threatened species. Version 2015.4. Accessed 8 Dec 2015. http://www.iucnredlist.org

Jackson DA, Mandrak NE (2002) Changing fish biodiversity: predicting the loss of cyprinid biodiversity due to global climate change. In: McGinn NA (ed) Fisheries in a changing climate. American Fisheries Society, Bethesda, pp 89-98

Jaeger KL, Olden JD, Pelland NA (2014) Climate change poised to threaten hydrologic connectivity and endemic fishes in dryland streams. Proc Natl Acad Sci 111:13894-13899

Kovach RP, Muhlfeld CC, Al-Chokhachy R, Dunham JB, Letcher BH, Kershner JL (2016) Impacts of climatic variation on trout: a global synthesis and path forward. Rev Fish Biol Fish 26:135-151

La Sorte FA, Jetz W (2012) Tracking of climatic niche boundaries under recent climate change. J Anim Ecol 81:914-925

Lawler JJ, Olden JD (2011) Reframing the debate over assisted colonization. Front Ecol Environ 9:569-574

Leathwick JR, Rowe D, Richardson J, Elith J, Hastie T (2005) Using multivariate adaptive regression splines to predict the distributions of New Zealand's freshwater diadromous fish. Freshw Biol 50:2034-2052

Leibold MA, Holyoak M, Mouquet N, Amarasekare P, Chase JM, Hoopes MF, Holt RD, Shurin JB, Law R, Tilman D, Loreau M, Gonzalez A (2004) The metacommunity concept: a framework for multi-scale community ecology. Ecol Lett 7:601-613

Loarie SR, Duffy PB, Hamilton HH, Asner GP, Field CB, Ackerly DD (2009) The velocity of climate change. Nature 462:1052-1055

Lynch AJ, Myers B, Chu C, Eby L, Falke J, Kovach R, Krabbenhoft T, Kwak T, Lyons J, Paukert C, Whitney J (2016) Climate change effects on North American inland fish populations and assemblages. Fisheries 41:346-361

MacCullagh P, Nelder JA (1984) Generalized linear models. University Press, Cambridge

MacKenzie DM, Nichols JD, Lachman GB, Droege S, Royle A, Langtimm CA (2002) Estimating site occupancy rates when detection probabilities are less than one. Ecology 83:2248-2255

Marshall RM, Robbles MD, Majka DR, Haney JA (2010) Sustainable water management in the southwestern United States: Reality or rhetoric? PLoS ONE 5:11687

Melles SJ, Chu C, Alofs KM, Jackson DA (2015) Potential spread of Great Lakes fishes given climate change and proposed dams: an approach using circuit theory to evaluate extinction risk. Landscape Ecol 30:919-935

Oksanen J, Blanchet FG, Kindt R, Legendre P, Minchin PR, O'Hara RB, Simpson GL, Solymos P, Stevens MHH, Wagner H (2015) Vegan: community ecology package. R package version 2.2-1

Olden JD, Poff NL (2005) Long-term trends of native and nonnative fish faunas in the American Southwest. Anim Biodivers Conserv 28:75-89

Olden JD, Poff N, Bestgen KR (2006) Life-history strategies predict fish invasions and extirpations in the Colorado River Basin. Ecol Monogr 76:25-40

Olden JD, Poff NL, Bestgen KR (2008) Trait synergisms and the rarity, extirpation, and extinction risk of desert fishes. Ecology 89:847-856 
Olden JD, Kennard MK, Leprieur F, Tedesco PA, Winemiller KO, García-Berthou E (2010) Conservation biogeography of freshwater fishes: past progress and future directions. Divers Distrib 16:496-513

Parmesan C, Yohe G (2003) A globally coherent fingerprint of climate change impacts across natural systems. Nature 421:37-42

Paukert CP, Pitts KL, Whittier JB, Olden JD (2011) Development and assessment of a landscape-scale ecological threat index for the Lower Colorado River Basin. Ecol Ind 11:304-310

Pearce J, Ferrier S (2000) Evaluating the predictive performance of habitat models developed using logistic regression. Ecol Model 133:225-245

Perry AL, Low PJ, Ellis JR, Reynolds JD (2005) Climate change and distribution shifts in marine fishes. Science 308:1912-1915

Pilger TJ, Gido KB, Propst DL (2010) Diet and trophic niche overlap of native and nonnative fishes in the Gila River, USA: implications for native fish conservation. Ecol Freshw Fish 19:300-321

Poff NL, Pyne MI, Bledsoe BP, Cuhaciyan CC, Carlisle DM (2010) Developing linkages between species traits and multiscaled environmental variation to explore vulnerability of stream benthic communities to climate change. J N Am Benthol Soc 29:1441-1458

Pool TK, Olden JD, Whittier JB, Paukert CP (2010) Environmental drivers of fish functional diversity and composition in the Lower Colorado River Basin. Can J Fish Aquat Sci 67:1791-1807

Radinger J, Wolter C (2013) Patterns and predictors of fish dispersal in rivers. Fish Fish 15:456-473

Rahel FJ, Olden JD (2008) Assessing the effects of climate change on aquatic invasive species. Conserv Biol 22:521-533

Roeckner E, Bäuml G, Bonaventura L, Brokopf R, Esch M, Giorgetta M, Hagemann S, Kirchner I, Kornblueh L, Manzini E, Rhodin A, Schlese U, Schulzweida U, Tompkins A (2003) The atmospheric general circulation model ECHAM5. Part I: model description. Max Planck Institute for Meteorology, Hamburg

Roy K, Hunt G, Jablonski D (2009) Phylogenetic conservatism of extinctions in marine bivalves. Science 325:733-737

Ruhi A, Olden JD, Sabo JL (2016) Declining streamflow induces collapse and replacement of native fish in the American Southwest. Front Ecol Environ 14:465-472

R Core Team (2015) R: A language and environment for statistical computing. R Foundation for Statistical Computing, Vienna, Austria. http://www.R-project.org/

Seager R, Ting M, Li C, Naik N, Cook B, Nakamura J, Liu H (2013) Projections of declining surface-water availability for the southwestern United States. Nat Clim Change 3:482-486

Seifert LI, Weithoff G, Gaedke U, Vos M (2015) Warminginduced changes in predation, extinction and invasion in an ectotherm food web. Oecologia 2015:1-12

Shmida A, Wilson MV (1985) Biological determinants of species diversity. J Biogeogr 12:1-20

Shurin JB, Clasen JL, Greig HS, Kratina P, Thompson PL (2012) Warming shifts top-down and bottom-up control of pond food web structure and function. Philos Trans R Soc B Biol Sci 367:3008-3017
Somero GN (2010) The physiology of climate change: how potentials for acclimatization and genetic adaptation will determine 'winners' and 'losers'. J Exp Biol 213:912-920

Stoll S, Kail J, Lorenz AW, Sundermann A, Haase P (2014) The importance of regional species pool, ecological species traits and local habitat conditions for the colonization of restored river reaches by fish. PLoS ONE 9:e84741

Stoner AMK, Hayhoe K, Yang X, Wuebbles DJ (2013) An asynchronous regional regression model for statistical downscaling of daily climate variables. Int $\mathrm{J}$ Climatol 33:2473-2494

Strecker AL, Olden JD, Whittier JB, Paukert CP (2011) Defining conservation priorities for freshwater fishes according to taxonomic, functional, and phylogenetic diversity. Ecol Appl 21:3002-3013

Sunday JM, Pecl GT, Frusher S, Hobday AJ, Hill N, Holbrook NJ, Edgar GF, Stuart-Smith R, Barrett N, Wernberg T, Watson RA, Smale DA, Fulton EA, Slawinski D, Feng M, Radford BT, Thompson PA, Bates AE (2015) Species traits and climate velocity explain geographic range shifts in an ocean-warming hotspot. Ecol Lett 18:944-953

Thomas CD (2010) Climate, climate change and range boundaries. Divers Distrib 16:488-495

Thuiller W, Lavergne S, Roquet C, Boulangeat I, Lafourcade B, Araujo MB (2011) Consequences of climate change on the tree of life in Europe. Nature 470:531-534

Urban MC (2015) Accelerating extinction risk from climate change. Science 348:571-573

van dan Wollenberg AL (1977) Redundancy analysis: an alternative for canonical correlation analysis. Psychometrika 42:207-291

Ward RD, Woodwark M, Skibinski DOF (1994) A comparison of genetic diversity levels in marine, freshwater, and anadromous fishes. J Fish Biol 44:213-232

Warren MS, Hill JK, Thomas JA, Asher J, Fox R, Huntley D, Roy B, Telfer MG, Jeffcoate S, Harding P, Jeffcoate G, Willis SG, Greatorex-Davies JN, Moss D, Thomas CD (2001) Rapid responses of British butterflies to opposing forces of climate and habitat change. Nature 414:65-69

Webb PW (1984) Form and function in fish swimming. Sci Am 251:72-82

Webb PW, Weihs D (1986) Functional locomotor morphology of early life history stages of fish. Trans Am Fish Soc 115:115-127

Whitney JE, Gido KB, Propst DL (2014) Factors associated with the success of native and nonnative species in an unfragmented arid-land riverscape. Can J Fish Aquat Sci 71:1134-1145

Whittier JB, Paukert CP, Olden JD, Pitts KL, Strecker AL (2011) Lower Colorado River Basin aquatic gap analysis project: final report. U.S. Geological Survey, Gap Analysis Program, Reston, Virginia, USA

Williams S, Shoo L, Isaac J, Hoffmann A, Langham G (2008) Towards an integrated framework for assessing the vulnerability of species to climate change. PLoS Biol 6:e325

Xenopoulos MA, Lodge DM, Alcamo J, Märker M, Schulze K, Van Vuuren DP (2005) Scenarios of freshwater fish extinctions from climate change and water withdrawal. Glob Change Biol 11:1557-1564 